\title{
Syphilitic balanitis of Follmann developing after the appearance of the primary chancre A case report
}

\author{
K. LEJMAN AND Z. STARZYCKI \\ From the Dermatological Clinic, Medical Academy, Kraków, Poland
}

Since the early descriptions of syphilitic balanitis of Follmann (SBF) (Follmann, 1931, 1934, 1939) with further communications on that topic reviewed by E. Follmann (1948) and Navarro-Martin (1950), as well as other reports published in the last two decades (Pailheret, Ferrieu, and Dauleux, 1953; Lejman, 1959; Matanić, 1965) a number of questions concerning this clinical manifestation have remained unanswered. Among them the following seem to be the most important:

(a) Can SBF develop after the appearance of the primary chancre?

(b) What is the histopathological picture of SBF ?

(c) How is T. pallidum distributed within SBF ?

The case reported here would seem to elucidate these points.

\begin{abstract}
Case report
An unmarried male mechanic aged 23 was admitted to the Dermatological Clinic on September 12, 1973, with extensive, relatively deep ulceration behind the glans penis. The base of the ulcer showed superficial necrosis; the borders were remarkably elevated and hard; light compression produced a profuse serous exudate. The glans, a little swollen, was covered with flat, whitish elevations, partially coalescent, and somewhat reminiscent of bacterial colonies on solid agar (Fig. 1); they were, however, not removable, and rubbing their surface yielded only a serous exudate. The prepuce was slightly swollen. There was bilateral inguinal lymphadenopathy, notably on the left side which was tender and the overlying skin was reddened. There were no skin lesions on the trunk and limbs or in the mouth.

The patient was of normal build, $168 \mathrm{~cm}$. tall, and weighed $58.5 \mathrm{~kg}$. He was afebrile; blood pressure $120 / 80$, pulse rate 76 and regular. He gave a history of intercourse with an unmarried girl on July 31, 1973, with the appearance 3 weeks later of an ulcer in the coronal sulcus which enlarged progressively. The lesions on the glans developed 2 weeks after the appearance of the ulcer.
\end{abstract}

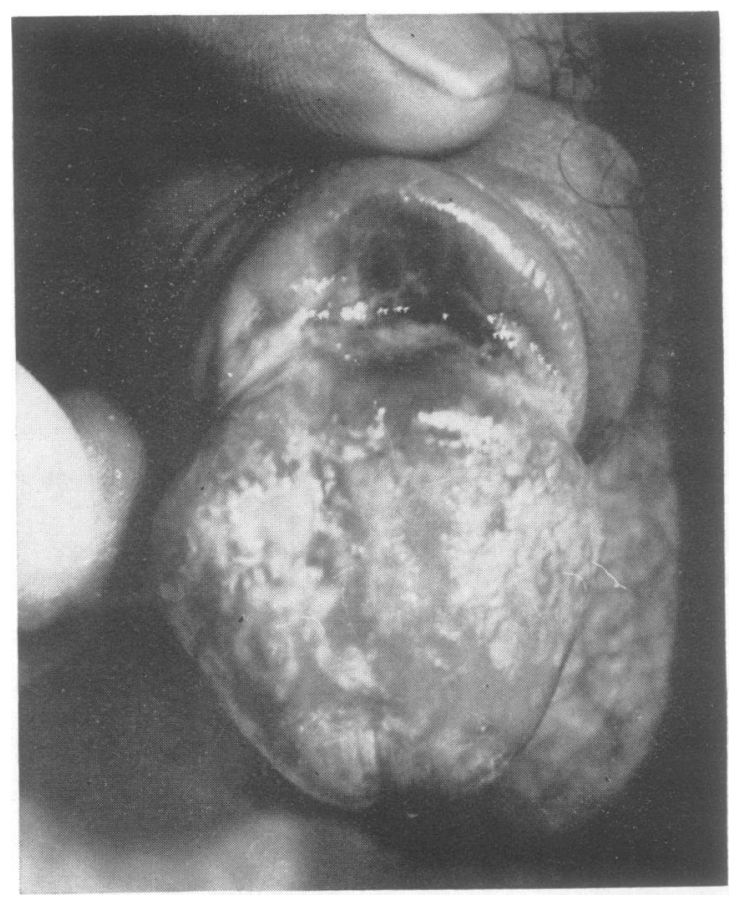

FIG. 1 Giant primary chancre and syphilitic balanitis of Follmann

\section{LABORATORY FINDINGS}

Dark-field examination of the serous exudate from the ulcer and the diffuse lesions on the glans revealed a large number of highly motile $T$. pallidum: these were also found in material obtained by puncture of the enlarged left inguinal lymph node. Saprophytic treponemes were absent. A Corynebacterium species was cultured from the ulcer and Staphylococcus pyogenes from the lymph node material. Examination of smears and cultures from the ulcer and the lesions on the glans, as well as biopsy material from the latter (stained by the Hotchkiss McManus method) were negative for both true fungi and Candida albicans.

Blood and urine examinations revealed nothing abnormal. 
SEROLOGICAL TESTS

\section{Blood}

The Wassermann reaction (WR) was strongly positive, the VDRL test reactive 1 in 64 , the TPI test positive with 100 per cent. immobilization, the FTA-200 test reactive 1 in 12,000, and the FTA-ABS test reactive.

\section{Cerebrospinal fluid}

Cell count 2 leucocytes/cu. mm.; protein $26 \mathrm{mg} . / 100 \mathrm{ml}$.; Pandy, Nonne-Appelt, and Weichbrodt tests weakly positive; WR and VDRL negative; TPI negative; FTA reactive $1: 10$.

\section{HISTOPATHOLOGY}

A biopsy of the flat non-ulcerated lesions on the glans was performed and the sections stained with haematoxylin and eosin (HE) as well as with the modification of the Krajian silver stain (Walter, Smith, Israel, and Gager, 1969).

In the sections stained with $\mathrm{HE}$ the following picture was observed (Fig.2): the epidermis was acanthotic, covered with a parakeratotic horny layer, and disrupted in the central part of the section by a large, flat, multilocular pustule; in the underlying, elongated rete ridges, the cells showed distinct polykaryosis with a varying intensity of staining. There was a massive transepidermal migration of leucocytes towards the surface, especially to the pustule. The papillae of the underlying connective tissue were densely infiltrated with histiocytes, lymphocytes, occasional plasma cells, and neutrophils. The capillaries were dilated, and contained many neutrophils, eosinophils, lymphocytes, and erythrocytes, which sometimes occluded the lumen. The walls of the capillaries and precapillaries were thickened and delaminated. The more deeply situated vessels and blood spaces were less affected. The sections stained with the modified Krajian method (Fig. 3) revealed an enormous accumulation of $T$. pallidum between the cells of the basal layer and between the cells of the adjoining one or two rows of the spinous layer, as well as in the region of the basal membrane. Although the treponemes in the walls of the nearby capillaries and in the connective tissue of the papillae were much more scarce, there seemed no other logical interpretation of the picture observed than that of an active penetration by these parasites through the walls of capillaries and the basal membrane into the epidermis, especially into the intercellular spaces.

\section{DIAGNOSIS, TREATMENT, AND COURSE OF THE ILLNESS}

Primary syphilis with a giant chancre behind the glans with subsequent development of syphilitic balanitis of Follmann was diagnosed. Treatment with intramuscular procaine penicillin 600,000 units daily was started. A Herxheimer reaction began $3 \mathrm{hrs}$ after the first injection and the fever reached $40^{\circ} \mathrm{C}$. $5 \mathrm{hrs}$ later. At the peak of

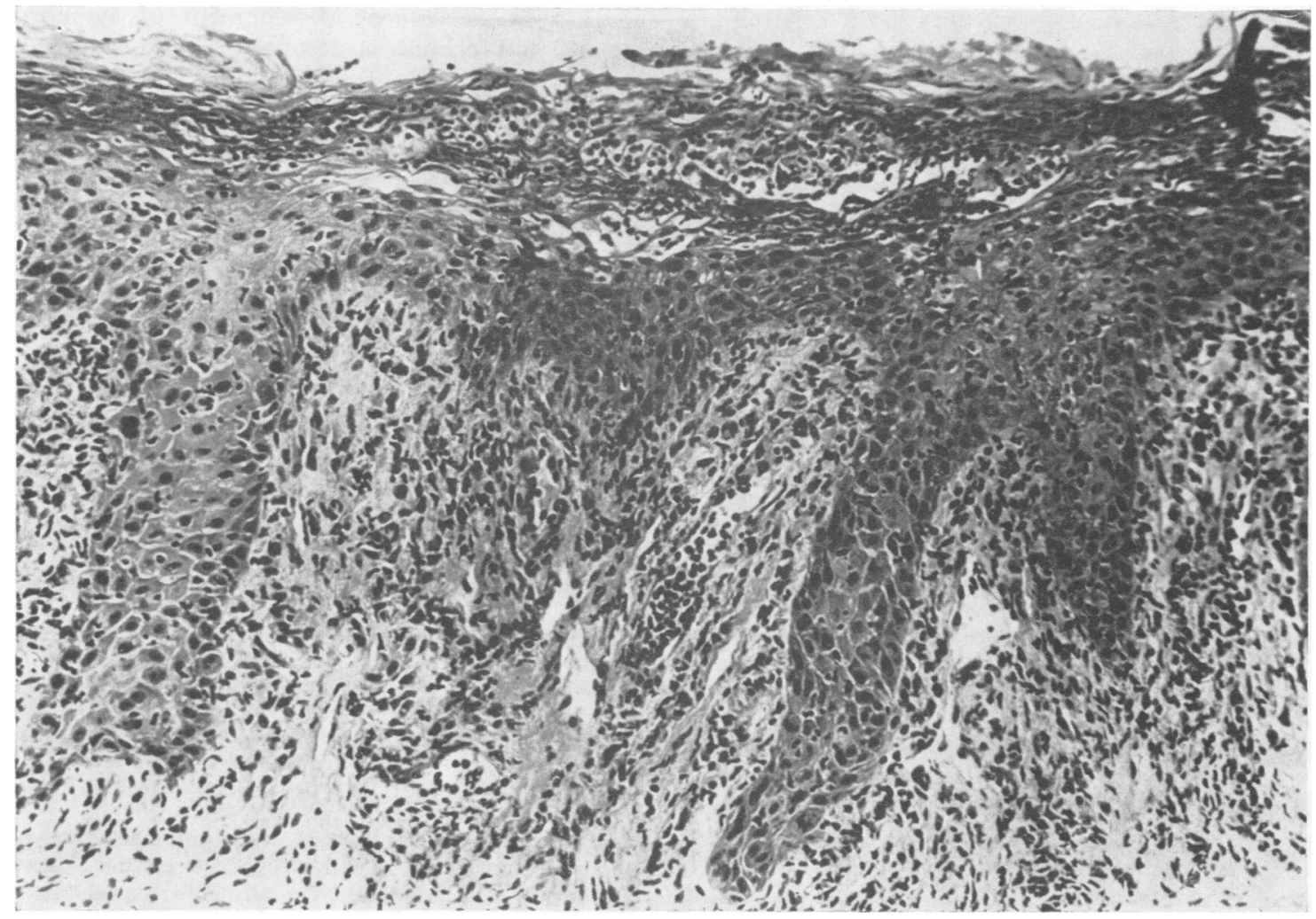

F I G. 2 Histopathology of syphilitic balanitis of Follmann. Haematoxylin and eosin. $\times 200$ 


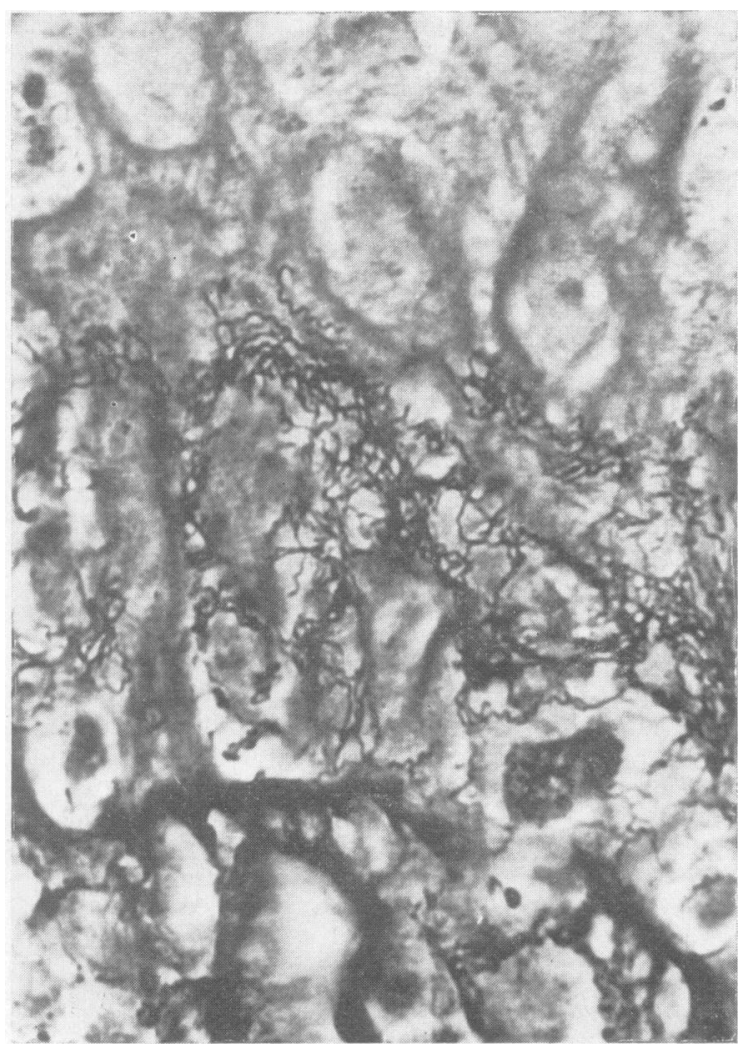

FIG. 3 Preponderantly intraepidermal localization of $\mathrm{T}$. pallidum in the lesions of syphilitic balanitis of Follmann. Modified Krajian silver stain. $\times 1,200$

the reaction a transient macular eruption on the trunk appeared with concomitant generalized enlargement of lymph nodes and oedema of the prepuce. The patient complained of sweating, headache, and weakness. Treponemes had disappeared from serum from the lesion $10 \mathrm{hrs}$ after the first injection of penicillin.

The procaine penicillin 600,000 units daily was continued for 32 days. The lesions on the glans resolved quickly in 6 days while the ulcer in the coronal sulcus healed 20 days later, leaving a fine scar.

\section{Discussion}

This case illustrates that typical SBF may develop not only instead of, before, or simultaneously with the primary chancre, but also afterwards. The presence of abundant $T$. pallidum not only in the serum expressed from the lesions of SBF, but also in the histopathological sections testifies to its aetiological role in SBF.

The superficial character of SBF can be explained by the preponderantly epidermal localization of $T$. pallidum in the intercellular spaces of the first, second, and third lower rows of cells. The localization of $T$. pallidum mainly to those parts of the epidermis overlying the papillae with dilated capillaries, including here and there $T$. pallidum in their walls, as well as the presence of the organism in the region of the basal membrane, undoubtedly indicates the haematogenous origin of the intraepidermal $T$. pallidum in SBF. It is possible that erections of the penis aided such spread from the chancre. From analogy with observations on the distribution of $T$. pallidum in condylomatous lesions (Lejman, unpublished), the possibility that intraepidermal multiplication of the organism is responsible for the mass accumulation in SBF should also be considered.

It is possible that cases of SBF are in reality much more frequent than is generally supposed; when treponemes are found in a primary chancre in the region of the glans or prepuce, we do not normally look further for them in the frequently accompanying inflamed glans penis.

\section{Summary}

A case of primary syphilitic chancre of the coronal sulcus with subsequent development of syphilitic balanitis of Follmann is described. The histopathological picture and preponderantly intraepidermal localization of $T$. pallidum in the lesions is discussed.

\section{References}

Follmann, E. (1948) Ann. Derm. Syph., 8 série, 8, 470

FollmanN, J. (1931) Orv. Hetil., 75, 680

- (1934) Derm. Wschr., 99, 1558

- (1939) Ann. Derm. Syph., 7 série, 10, 681

Lejman, K. (1959) Hautarzt, 10, 249

Matanić, V. (1965) Ibid., 16, 437

NAVARRO-MarTIN, A. (1950) Act. dermo-sifiliogr. (Madr.), 61, 791

PailHeret, Ferrieu, and Dauleux (1953) Bull. Soc. franc. Derm., No. 4, 401

WALTER, E. K., SMith, J. LAWTON, IsRakL, C. W., and GAGER, W. E. (1969) Brit. F. vener. Dis., 45, 6

Balanite syphilitique de Follmann développée après l'apparition d'un chancre primaire

\section{SOMMAIRE}

Il est décrit un cas de chancre syphilitique primaire du sillon coronaire suivi par le développement d'une balanite syphilitique de Follmann. On discute l'aspect histopathologique et la localisation intra-épidermique prépondérante de $T$. pallidum. 